\title{
PERANCANGAN WEBSITE LEMBAGA PENELITIAN PENGABDIAN MASYARAKAT BERBASIS KEWIRAUSAHAAN PADA SEKOLAH TINGGI TEKNOLOGI INDUSTRI PADANG
}

\author{
Veni Wedyawati ${ }^{1)}$, Eko Amri Jaya ${ }^{2)}$ \\ ${ }^{1,2}$ Program Studi Sistem Informasi Sekolah Tinggi Teknologi Industri (STTIND) Padang \\ Email : ${ }^{1}$ venywedya@yahoo.com, ${ }^{2}$ ekoamzari26@gmail.com
}

\begin{abstract}
Research and Community Service Institute (LPPM) of STTIND Padang is one of the academic components that conducts some of the main tasks and functions of STTIND in the field of Research and Community Service. The absence of facility in form of a website to promote LPPM STTIND Padang to the society and storage to systematically keep all records of research and community services as well as attempt to commercialize the products of research conducted by LPPM STTIND Padang to the publics. Therefore, it is necessary to design a website devoted to the promotion of LPPM STTIND Padang to the publics as well as to the commercialization of research products.
\end{abstract}

Keywords : System, Information, Website

\section{Abstrak}

Lembaga Penelitian Pengabdian Masyarakat (LPPM) STTIND Padang adalah unsur pelaksana akademik yang melaksanakan sebagian tugas pokok dan fungsi STTIND Padang di bidang Penelitian dan Pengabdian Kepada Masyarakat. Belum adanya wadah atau website untuk memperkenalkan Lembaga Penelitian Pengabdian Masyarakat (LPPM) STTIND Padang ke masyarakat, dan belum tersimpannya rekapitulasi penelitian dan pengabdian masyarakat secara terstruktur, serta belum dipasarkannya produk hasil penelitian yang ada pada Lembaga Penelitian Pengabdian Masyarakat (LPPM) STTIND Padang ke masyarakat. Maka dari itu dibutuhkan sebuah website untuk memperkenalkan Lembaga Penelitian Pengabdian Masyarakat (LPPM) STTIND Padang ke masyarakat serta memasarkan produk hasil penelitian yang ada pada Lembaga Penelitian Pengabdian Masyarakat (LPPM) STTIND Padang.

Kata Kunci : Sistem, Informasi, Website

\section{PENDAHULUAN}

LPPM STTIND Padang adalah suatu perangkat akademik yang menjalankan sebagian tugas pokok dan fungsi STTIND Padang di bidang Penelitian dan PKM. LPPM STTIND Padang mempunyai tugas melakukan koordinasi dan mendokumentasi pelaksanaan kegiatan penelitian dan pengabdian kepada masyarakat serta ikut mengusahakan pengendalian administrasi sumber daya yang diperlukan.

Belum adanya wadah atau website untuk memperkenalkan Lembaga Penelitian Pengabdian Masyarakat (LPPM) STTIND Padang ke masyarakat, dan belum tersimpannya rekapitulasi penelitian dan pengabdian masyarakat secara terstruktur, serta belum dipasarkannya produk hasil penelitian yang ada pada Lembaga Penelitian
Pengabdian Masyarakat (LPPM) STTIND Padang ke masyarakat.

Untuk memperkenalkan Lembaga Penelitian Pengabdian Masyarakat (LPPM) STTIND Padang dalam memasarkan produk hasil penelitian agar dapat dikenal oleh masyarakat, supaya tersimpannya rekapitulasi penelitian dan pengabdian masyarakat secara terstruktur maka dibutuhkan sebuah website. Website itu sendiri merupakan kumpulan halamanhalaman yang berisi informasi yang disimpan diinternet yang bisa diakses atau dilihat melalui jaringan internet pada perangkat-perangkat yang bisa mengakses internet itu sendiri seperti komputer.

Jadi, dalam penelitian ini peneliti merancang sebuah website berbasis kewirausahaan dengan judul : "Perancangan Website Lembaga Penelitian Pengabdian Masyarakat 
(LPPM) STTIND Padang Berbasis Kewirausahaan".

Rumusan masalah yaitu bagaimana merancang, memperkenalkan, memasarkan, menyimpan rekapitulasi penelitian pada sebuah website Lembaga Penelitian Pengabdian Masyarakat (LPPM) STTIND Padang berbasis kewirausahaan secara terstruktur?

\section{METODOLOGI PENELITIAN}

\subsection{Jenis Penelitian}

Jenis penelitian yang penulis lakukan adalah penelitian Terapan (Applied research). Penelitian terapan adalah penelitan yang diarahkan untuk mendapatkan informasi yang dapat digunakan untuk memecahkan masalah.

\subsection{Tempat dan Waktu Penelitian}

Penelitian berlokasi di Jln. Prof. Dr. Hamka No. 121 Padang pada Lembaga Penelitian Pengabdian Masyarakat (LPPM) STTIND Padang. Penelitian telah dilaksanakan pada tanggal 1 Maret 2017 1 April 2017.

\subsection{Variabel Penelitian}

Adapun sebuah Variabel penelitian yaitu semua hal berhubungan dan yang terkait akan menjadi objek pengamatan dan penelitian. Jadi pada penelitian ini penulis menggunakan variabel data Lembaga Penelitian Pengabdian Masyarakat.

\subsection{Langkah-langkah Metode Penelitian}

1. Langkah-langkah penelitian yaitu menyediakan data-data penelitian, menyediakan software, setelah website dirancang maka semua data akan di input, dan melakukan
2. implementasi, terakhir melakukan testing.

\subsection{Data dan sumber data}

Data primer atau data langsung merupakan metode pengumpulan data

dilakukan oleh peneliti dengan metode bertemu dengan objek secara langsung (Interview) dan metode penelitian ke lapangan (Observasi)

Data sekunder merupakan data yang diperoleh dari literatur, jurnal-jurnal dan studi kepustakaan yang berhubungan dengan penelitian dan mendukung penelitian ini.

\section{ANALISA DAN DESAIN SISTEM \\ 3.1 Desain Sistem}

Desain sistem merupakan sebuah teknik pemecahan masalah yang saling melengkapi yang merangkai kembali bagian-bagian komponen menjadi sistem yang lengkap. Adapun sebuah Tujuan sistem adalah agar pengambilan keputusan dapat dilakukan secara efektif. Sehingga dapat menghemat waktu dan biaya.

\subsection{Use Case Diagram}

Use Case Diagram merupakan gambaran informasi dari suatu bagian ke bagian yang lain dimana informasi yang dihasilkan akan diproses secara komputerisasi. Untuk lebih jelas dapat dilihat pada gambar dibawah ini: 


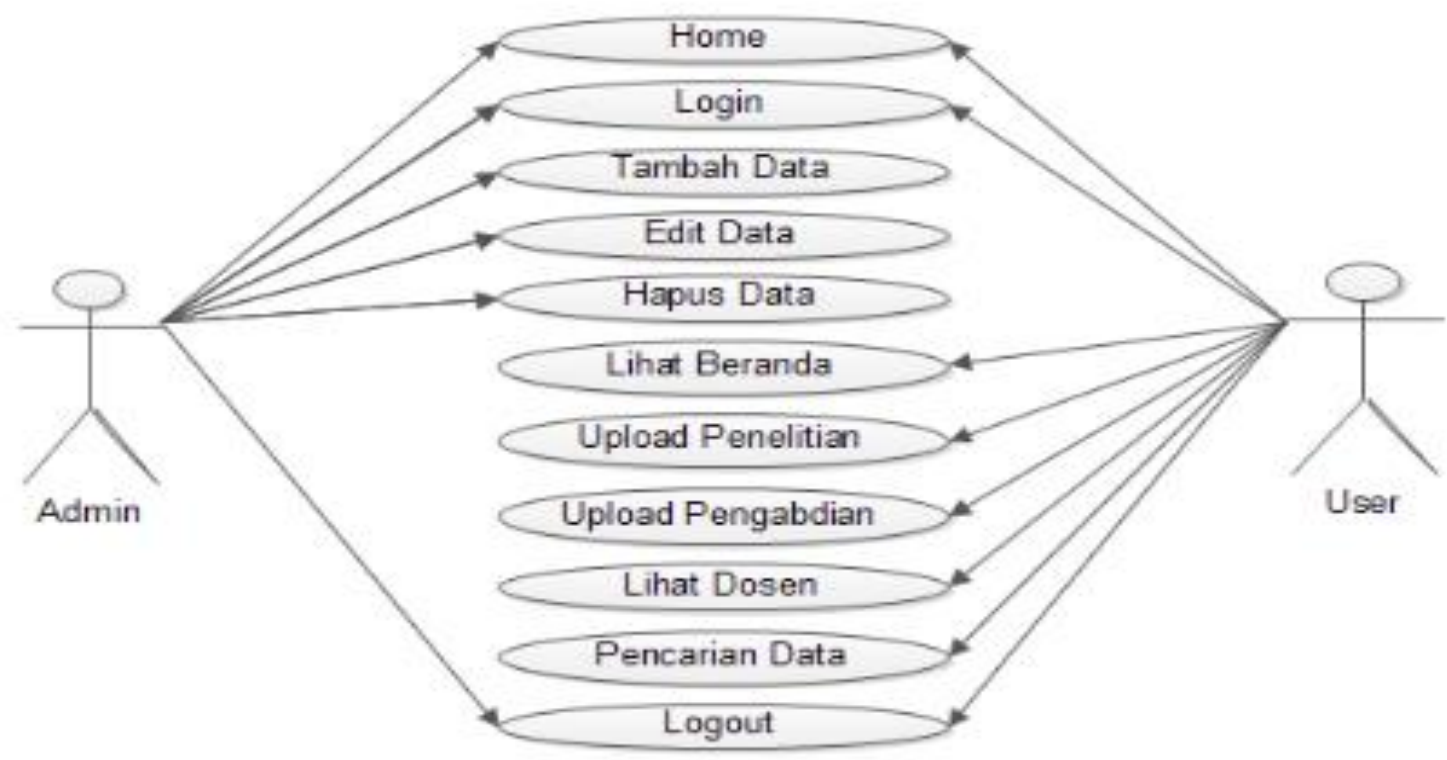

\section{Gambar 4.1 Use Case Diagram}

\subsection{Class Diagram}

Adapun tahap berikutnya adalah merancang dan menganalisa class-class sebagai berikut disimpulkan dalam use case diagram. Class yang diperoleh dari hasil analisa akan disajikan dalam gambar 4.2 berikut ini :

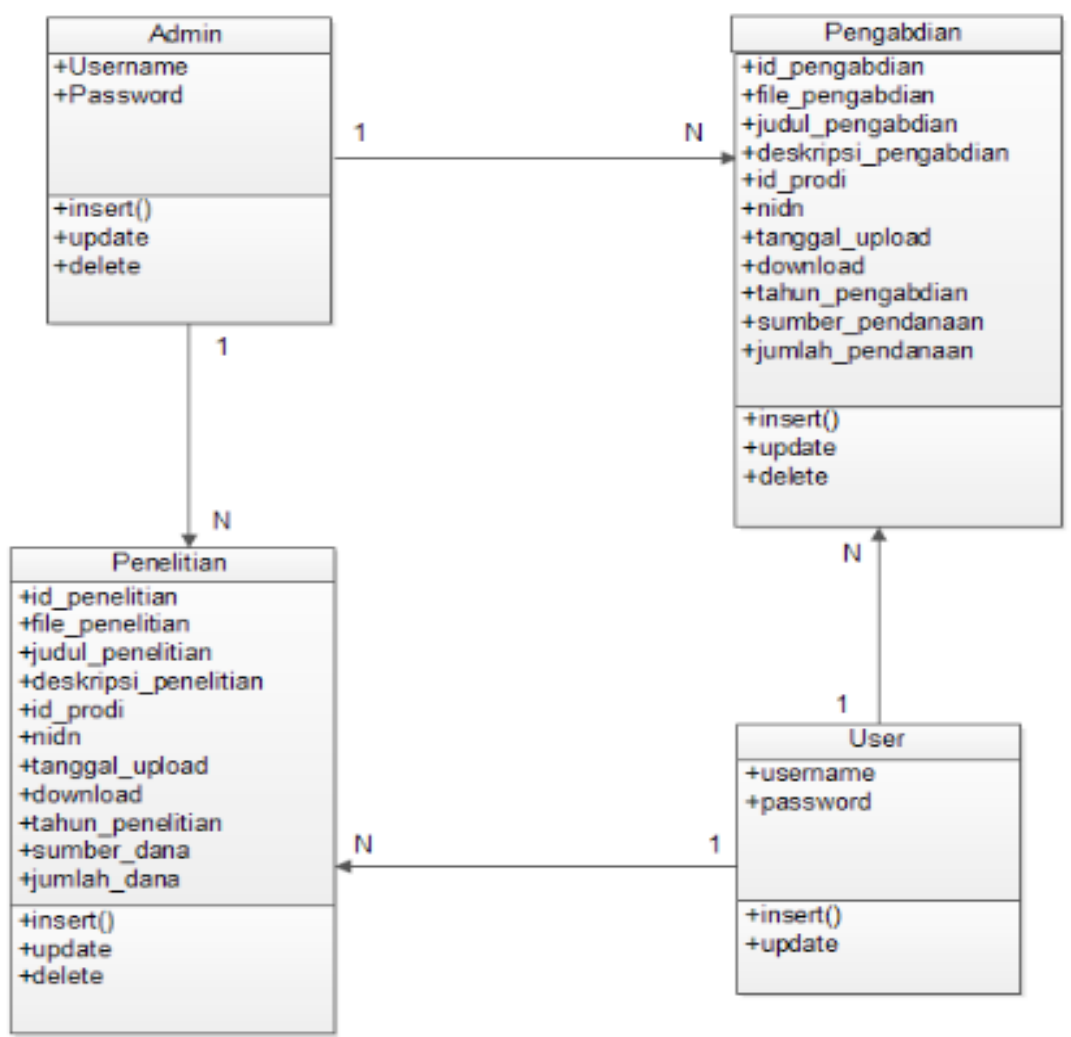

Gambar 4.2 Class Diagram 


\subsection{Sequence Diagram}

Sequence diagram digunakan untuk menjabarkan aktifitas yang ada pada use case kepada level yang lebih detail, berikut gambar sequence diagram:

1. Sequence diagram untuk admin

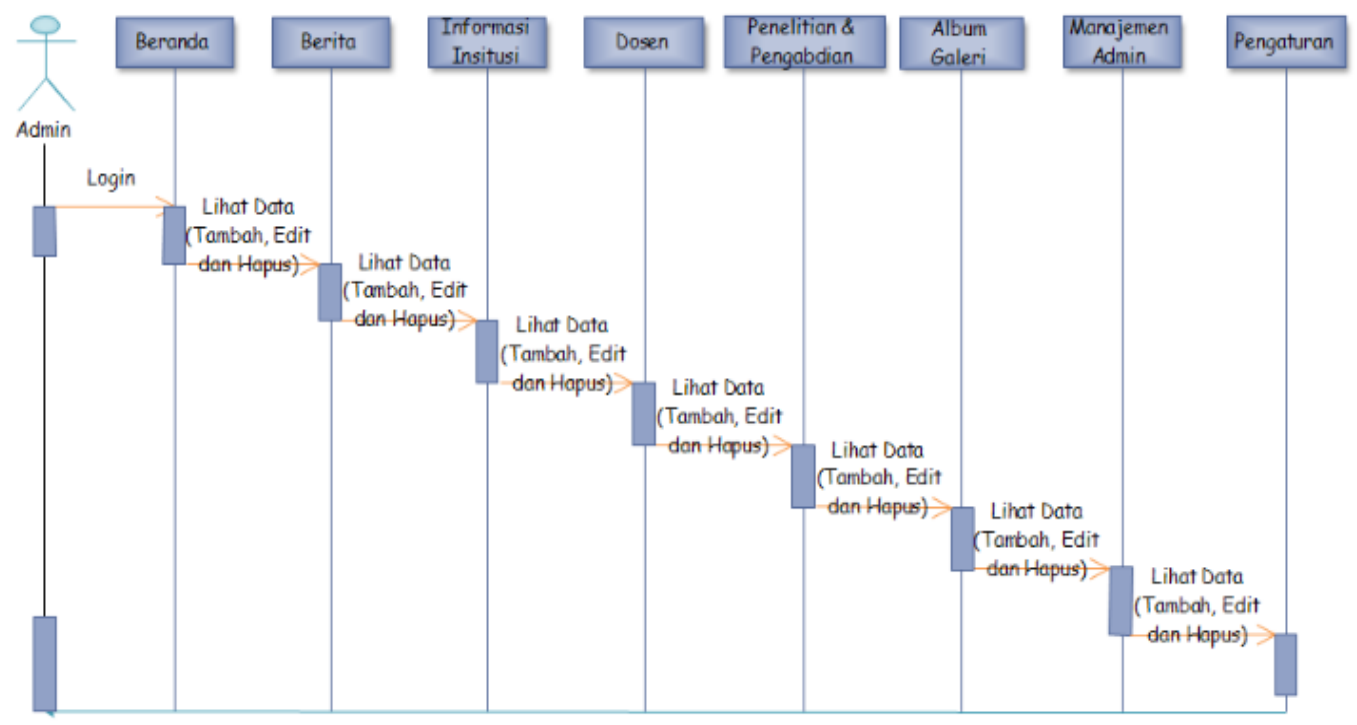

Gambar 4.3 Sequence Diagram Admin

2. Sequence diagram untuk user

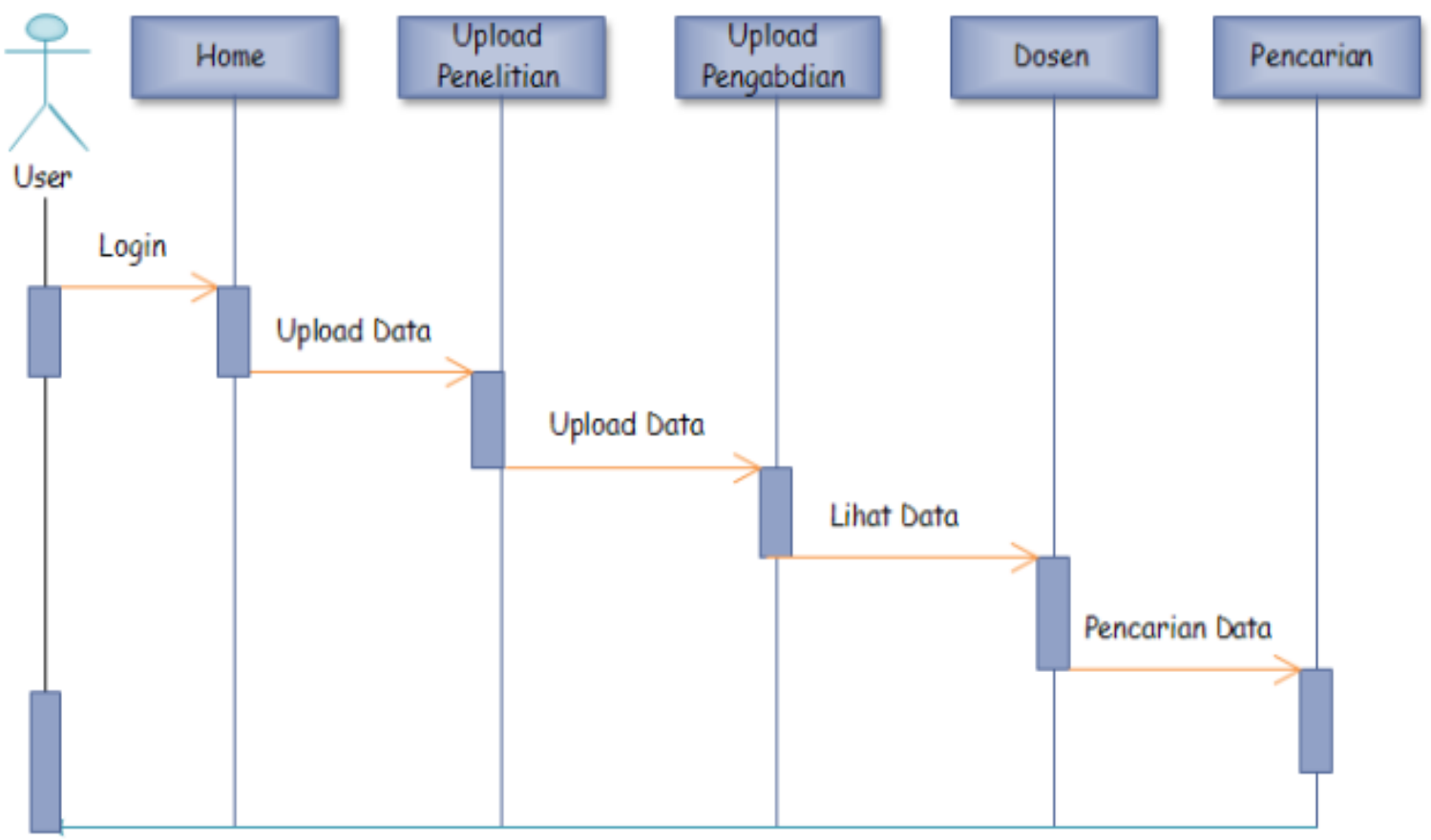

Gambar 4.4 Sequence Diagram User

\subsection{Activity Diagram}

Activity diagram digunakan untuk memperlihatkan aliran dari suatu aktivitas ke aktivitas lainya dalam suatu sistem. Berikut gambar activity diagram. 
1. Activity Diagram untuk Admin

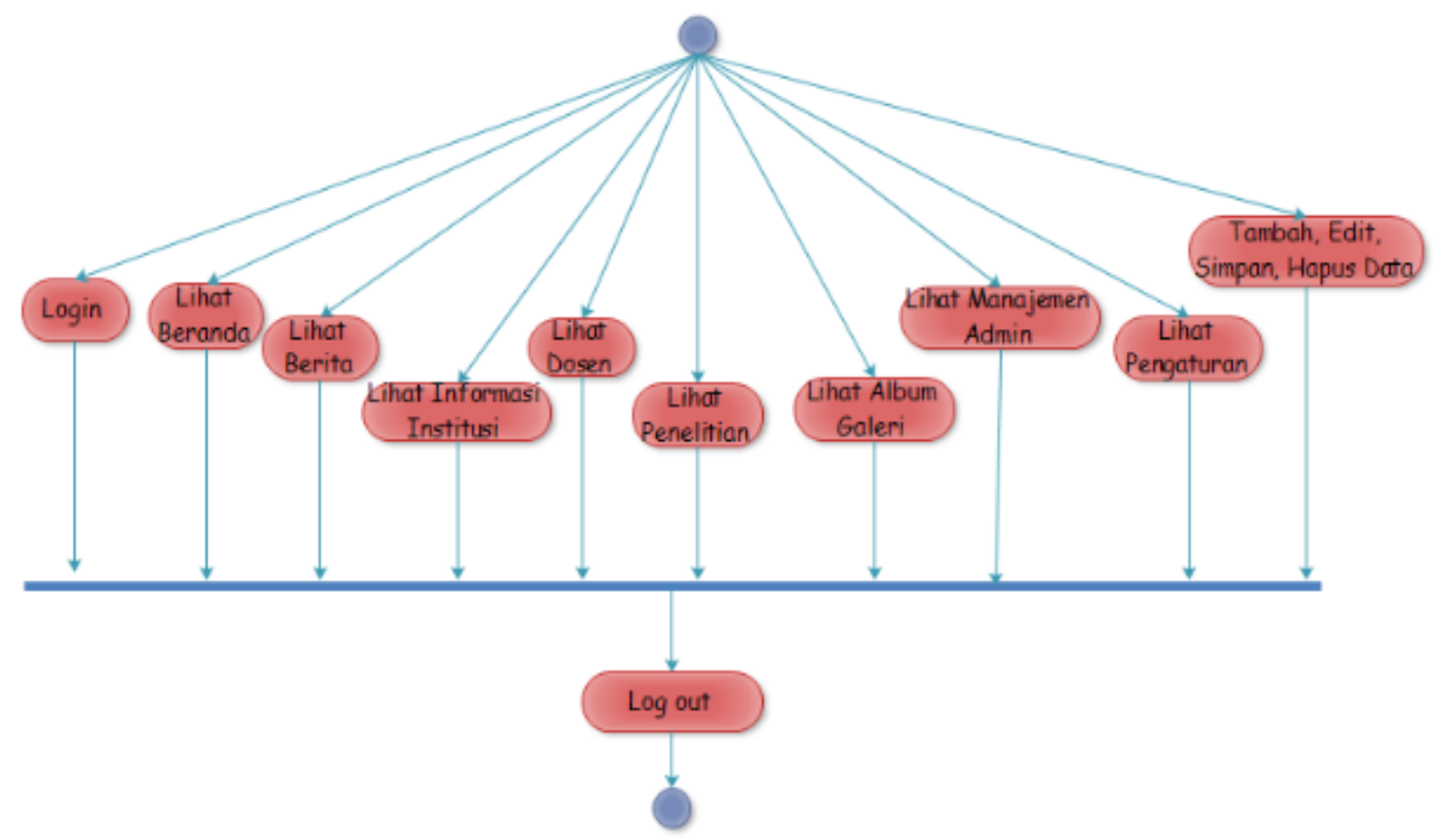

Gambar 4.5 Activity Diagram Admin

2. Activity Diagram untuk User

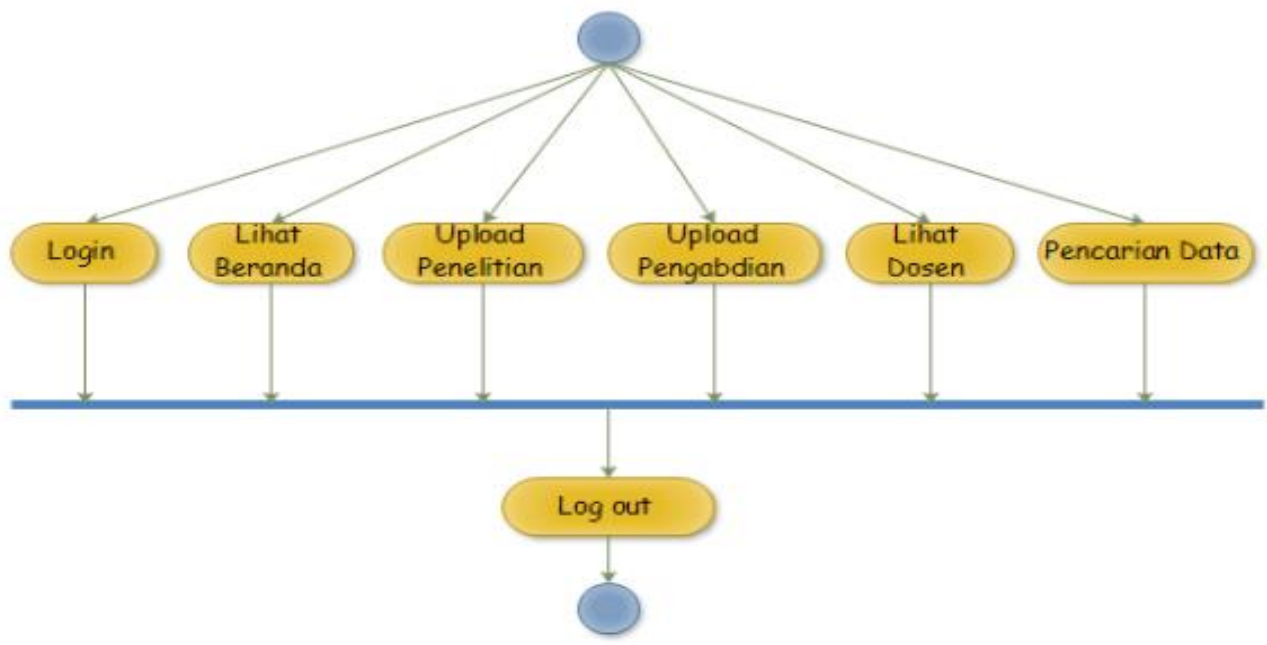

Gambar 4.6 Activity Diagram User

\section{IMPLEMENTASI SISTEM}

4.1 Menu Utama

Menu utama ini menampilkan menu Home, Profil, Penelitian dan Pengabdian, Berita, Informasi, Galeri, Prodk yang dapat di akses user. 


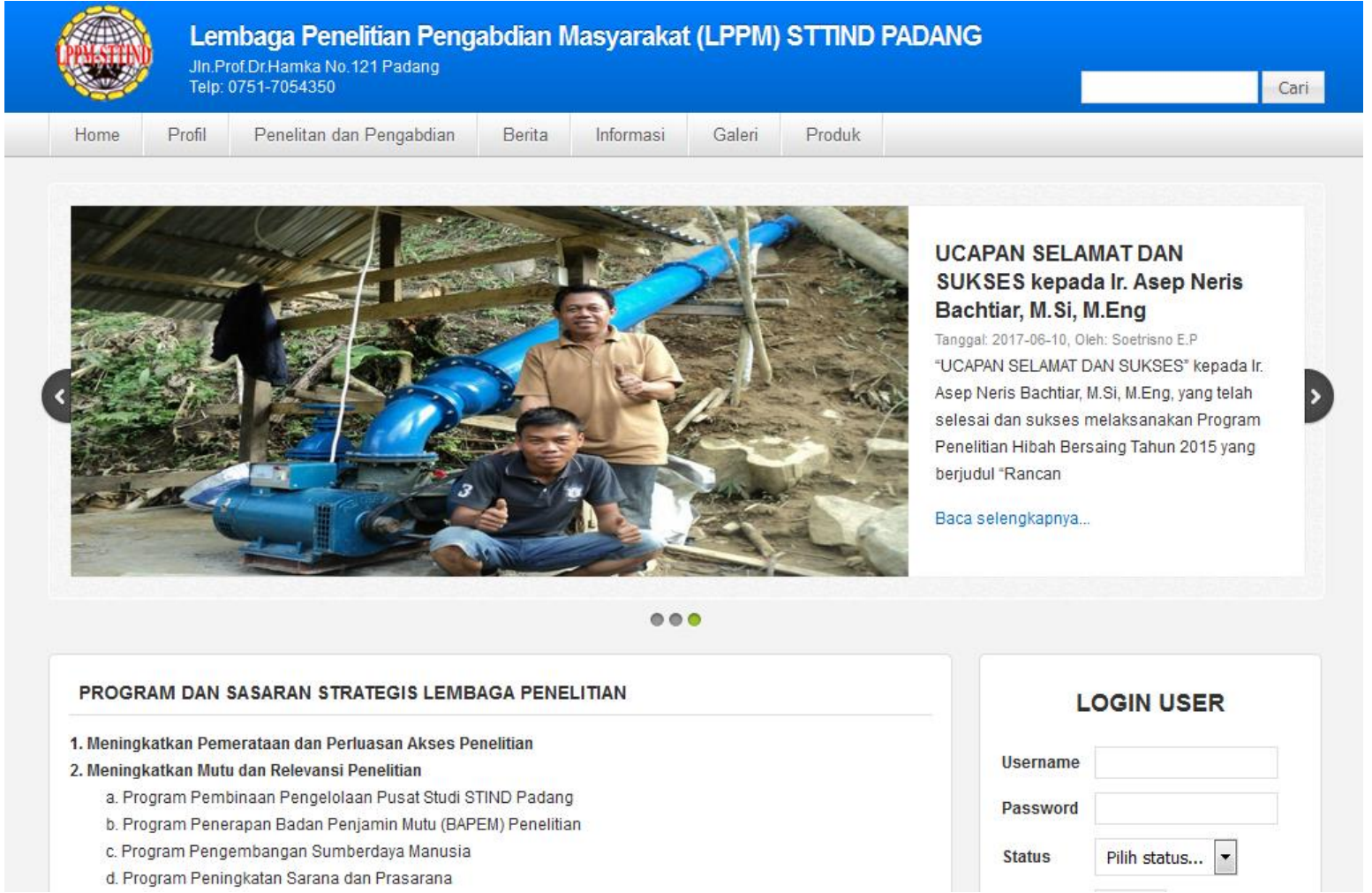

\section{Gambar 5.1 Menu Utama}

\subsection{Menu Login User}

Hanya user terdaftar yang memiliki akses ke menu ini. Menu ini berguna untuk mengupload penelitian bagi user.

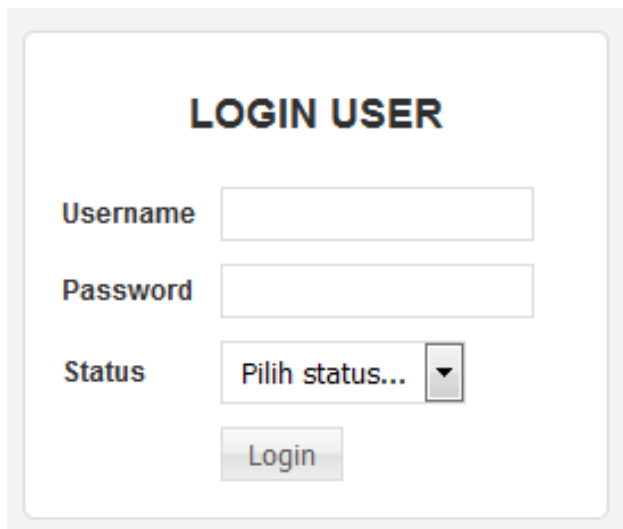

\section{Gambar 5.2 Menu Login User}

\subsection{Menu Beranda User}

Merupakan menu awal yang tampil ketika user berhasil login. Pada menu ini user bisa melihat penelitian terbaru, penelitian terpopuler dan juga informasi login yang berisi tentang upload penelitian, upload pengabdian, dosen dan pencarian. 


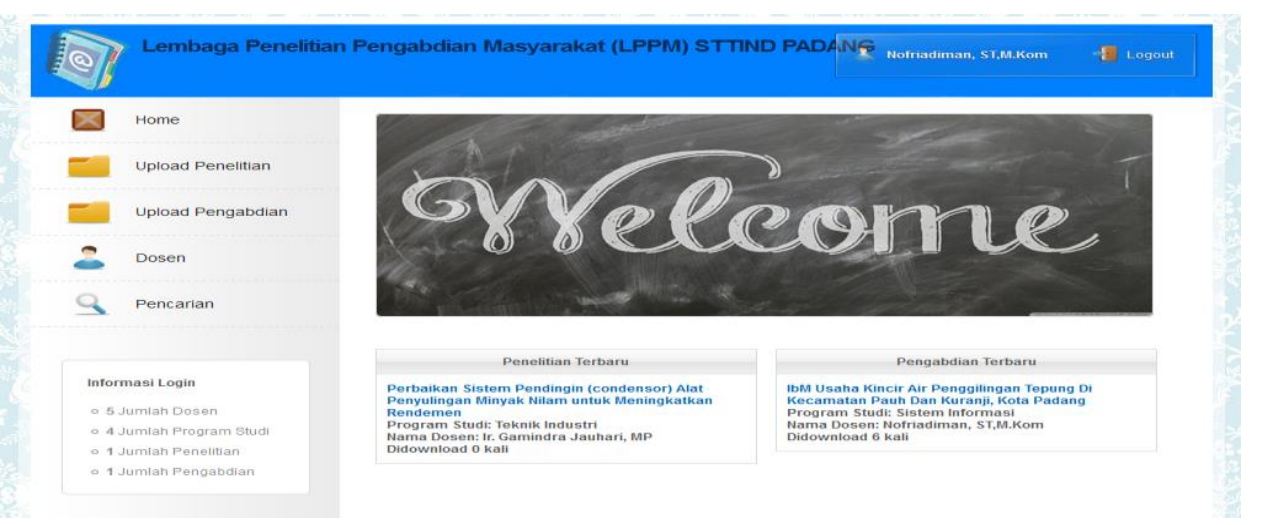

\section{Gambar 5.3 Menu Beranda User}

\subsection{Menu Upload Penelitian User}

Pada menu ini user bisa mengupload penelitian yang telah dilakukan.

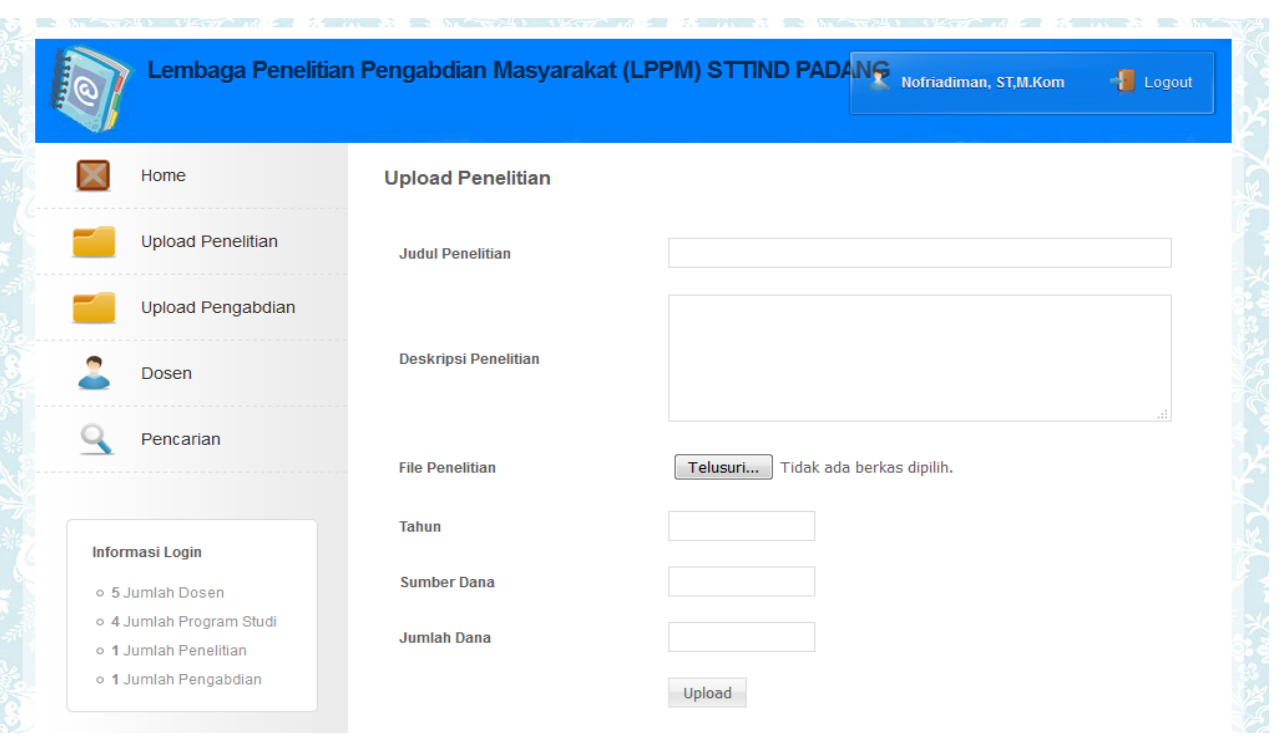

\section{Gambar 5.4 Menu Upload Penelitian User}

\subsection{Menu Upload Pengabdian User}

Pada menu ini user bisa mengupload pengabdian yang telah dilakukan.

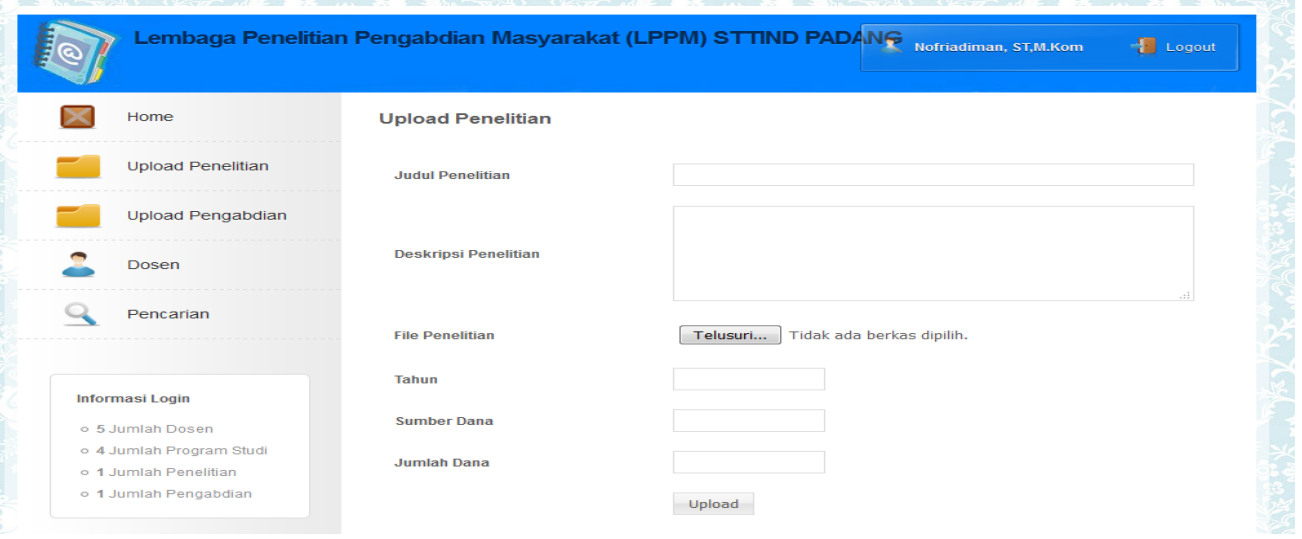

Gambar 5.5 Menu Upload Pengabdian User 


\subsection{Menu Produk}

Menampilkan produk hasil penelitian yang ada pada Lembaga Penelitian Pengabdian Masyarakat (LPPM) STTIND Padang.

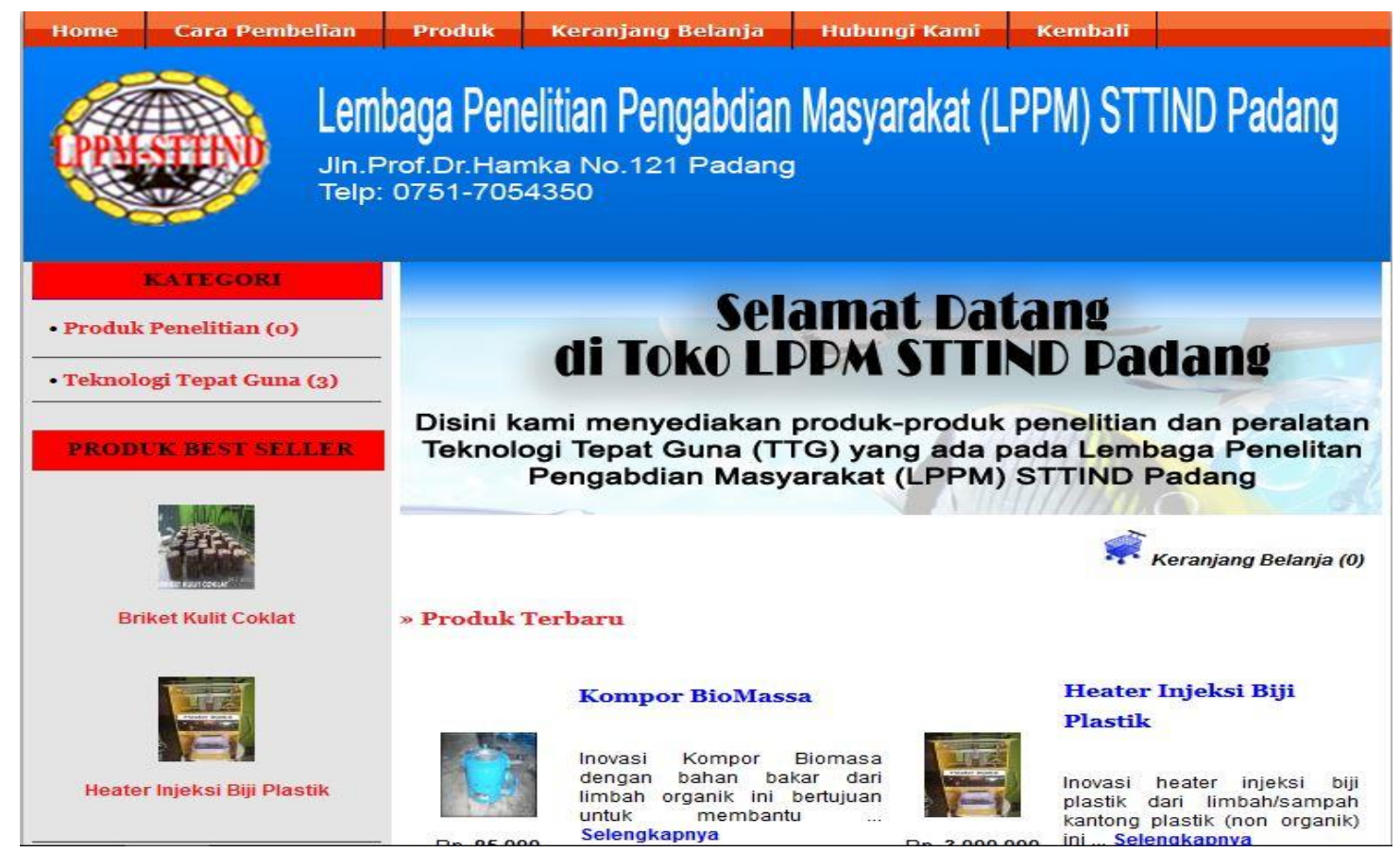

Gambar 5.6 Menu Produk

\section{KESIMPULAN}

Berdasarkan hasil penelitian pada perancangan website Lembaga Penelitian Pengabdian Masyarakat (LPPM) STTIND Padang, maka penulis mengambil kesimpulan, sebagai berikut :

1. Memberikan wadah untuk memperkenalkan Lembaga Penelitian Pengabdian Masyarakat (LPPM) STTIND Padang dan dapat memasarkan produk hasil penelitian yang ada pada Lembaga Penelitian Pengabdian Masyarakat (LPPM) STTIND Padang kepada masyarakat.

2. Dapat tersimpannya rekapitulasi penelitian dan pengabdian masyarakat yang ada pada Lembaga Penelitian Pengabdian Masyarakat (LPPM) STTIND Padang secara terstruktur.

3. Bisa memasarkan produk-produk penelitian yang ada pada Lembaga Penelitian Pengabdian Masyarakat
(LPPM) STTIND Padang ke masyarakat.

\section{DAFTAR KEPUSTAKAAN}

Ernita, Tri. Dkk. Buku Panduan Penulisan dan Ujian Skripsi. Padang : Universitas STTIND Padang. 2015-2016.

Jogiyanto. Analisis dan Desain Sistem Informasi, Penerbit Andi Offset. Yogyakarta, 2002

Kendall, K.E \& Kendall, J.E, Al Hmdany Hafedh, Analisis dan Perancangan Sistem (Jilid 1) edisi kelima, PT Prenhallindo dan Pearson Education Asia Pte.Ltd, Jakarta, 2003.

Madcoms. Kupas Tuntas Adobe Dreamweaver CS6 Dengan Pemrograman PHP \& MYSQL. Yogyakarta : Andi Publisher. 2013.

Stair, M. Ralph and George, W. Reynolds. Principles of Information Systems : A Managerial Approach $\left(9^{\text {th }}\right.$ 
edition). Australia : Thomson

Course Technology. 2010.

Sukirno, Sadono. Makroekonomi : Teori

Pengantar. Jakarta : PT. Raja

Grafindo Persada. 2004. 


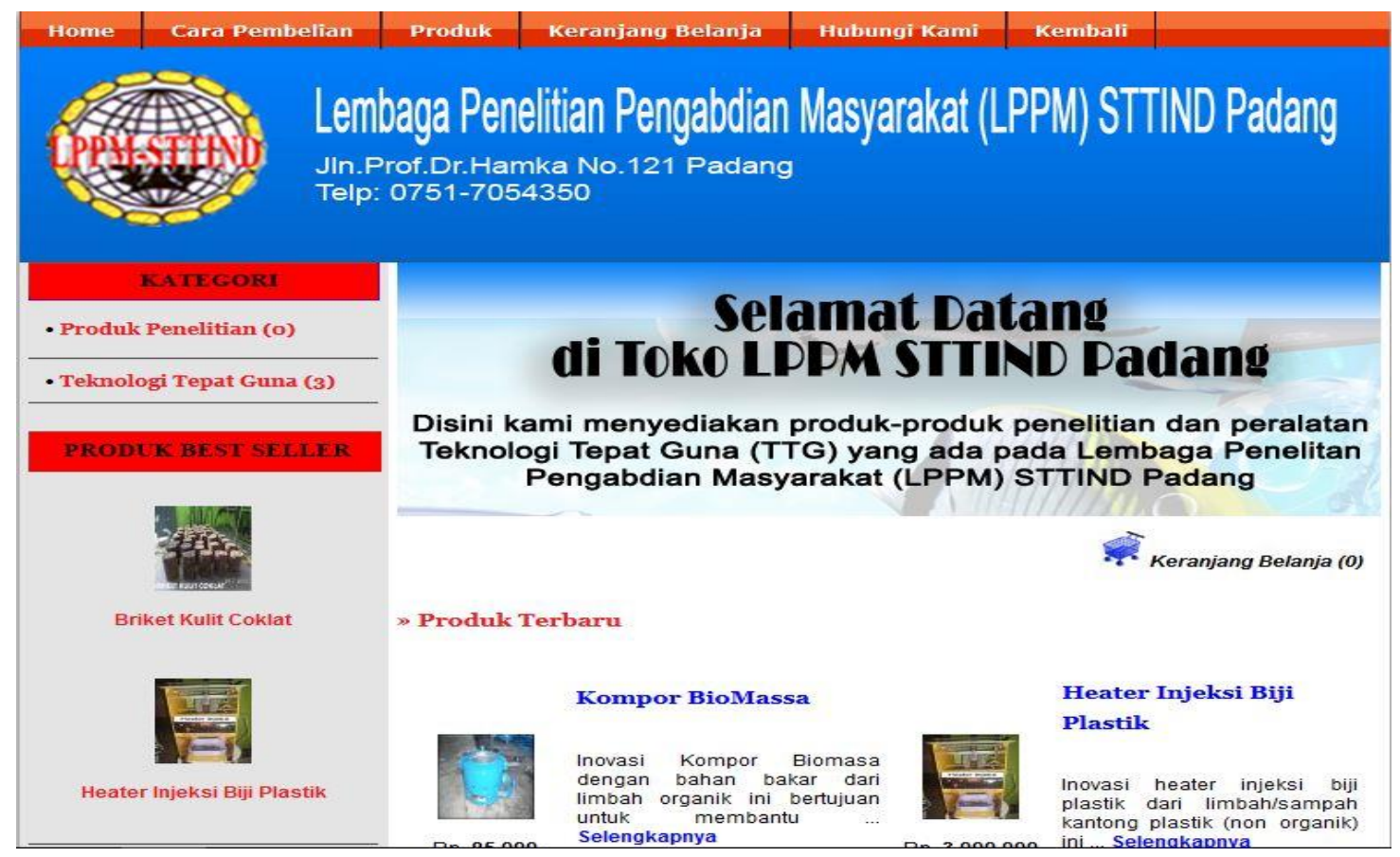

\section{Gambar 5.6 Menu Produk}

\section{KESIMPULAN}

Berdasarkan hasil penelitian pada perancangan website Lembaga Penelitian Pengabdian Masyarakat (LPPM) STTIND Padang, maka penulis mengambil kesimpulan, sebagai berikut :

4. Memberikan wadah untuk memperkenalkan Lembaga Penelitian Pengabdian Masyarakat (LPPM) STTIND Padang dan dapat memasarkan produk hasil penelitian yang ada pada Lembaga Penelitian Pengabdian Masyarakat (LPPM) STTIND Padang kepada masyarakat.

5. Dapat tersimpannya rekapitulasi penelitian dan pengabdian masyarakat yang ada pada Lembaga Penelitian Pengabdian Masyarakat (LPPM) STTIND Padang secara terstruktur.

6. Bisa memasarkan produk-produk penelitian yang ada pada Lembaga
Penelitian Pengabdian Masyarakat (LPPM) STTIND Padang ke masyarakat.

\section{DAFTAR KEPUSTAKAAN}

Ernita, Tri. Dkk. Buku Panduan Penulisan dan Ujian Skripsi. Padang : Universitas STTIND Padang. 20152016.

Jogiyanto. Analisis dan Desain Sistem Informasi, Penerbit Andi Offset. Yogyakarta, 2002

Kendall, K.E \& Kendall, J.E, Al Hmdany Hafedh, Analisis dan Perancangan Sistem (Jilid 1) edisi kelima, PT Prenhallindo dan Pearson Education Asia Pte.Ltd, Jakarta, 2003.

Madcoms. Kupas Tuntas Adobe Dreamweaver CS6 Dengan Pemrograman PHP \& MYSQL. Yogyakarta : Andi Publisher. 2013. 
Stair, M. Ralph and George, W. Reynolds. Principles of Information Systems : A Managerial Approach (9 $9^{\text {th }}$ edition). Australia : Thomson Course Technology. 2010.

Sukirno, Sadono. Makroekonomi : Teori Pengantar. Jakarta : PT. Raja Grafindo Persada. 2004. 